\title{
Tick- and flea-borne rickettsioses in Tizi-Ouzou, Algeria: Implications for travel medicine
}

\author{
Hayet Bouchaib $^{\mathrm{a}}$, Carole Eldin ${ }^{\mathrm{b}}$, Maureen Laroche ${ }^{\mathrm{b}}$, Didier Raoult ${ }^{\mathrm{c}}$, Philippe Parola ${ }^{\mathrm{b}, *}$ \\ ${ }^{\text {a }}$ Service des Maladies Infectieuses, Centre Hospitalo-Universitaire de Tizi- Ouzou, Algeria \\ ${ }^{\mathrm{b}}$ Aix Marseille Univ, IRD, AP-HM, SSA, VITROME, IHU-Méditerranée Infection, Marseille, France \\ ${ }^{\mathrm{c}}$ Aix Marseille Univ, IRD, AP-HM, MEPHI, IHU-Méditerranée Infection, Marseille, France
}

\section{A R T I C L E I N F O}

\section{Keywords:}

Rickettsia

Algeria

Tizi-ouzou

Eschar

Rash

Murine typhus

Mediterranean spotted fever

R. felis

Swab

\begin{abstract}
A B S T R A C T
Background: In Algeria, Mediterranean spotted fever (MSF), caused by Rickettsia conorii conorii and transmitted by Rhipicephalus sanguineus ticks, is endemic. However, the documentation of cases is rare due to a lack of laboratory facilities. Our aim was to screen for rickettsioses in patients with fever, rash and a possible inoculation eschar. Materials and methods: Between 2013 and 2015, patients with a fever and a rash presenting at hospitals in the Tizi-Ouzou region were prospectively included in our study. Sera were screened using Indirect Immunofluorescence Assay (IFA) and qPCR was performed on swab samples from eschars.

Results: One hundred and sixty-six patients were included. For 57 patients, MSF due to R. conorii conorii was diagnosed by serology and qPCR on a swab eschar sample. Three patients were diagnosed with murine typhus, a flea borne rickettsiosis. In addition, two patients had a positive serology in IgM for R. felis. For nine patients, serology for rickettsiosis was positive, but the specific rickettsia involved could not be determined. Nine patients had a severe disease with neurological involvement or multi-organ failure.

Conclusion: Clinicians should routinely screen for rickettsioses in patients and travellers presenting with a rash upon return from Algeria. Doxycycline treatment must be given promptly because the prognosis can be severe.
\end{abstract}

\section{Introduction}

Spotted fever group (SFG) rickettsioses are caused by obligate intracellular bacteria belonging to the genus Rickettsia. They are transmitted to humans by arthropods, mainly ticks [1]. In 1910, the first case of Mediterranean spotted fever (MSF) was reported in Tunisia. The causative agent was subsequently named Rickettsia conorii, and its vector, the brown dog tick Rhipicephalus sanguineus, was described in the 1930s [1]. Tick-borne rickettsioses are now recognised as emerging worldwide, with more than fifteen new tick-borne rickettsial agents identified as human pathogens in the past 30 years [2]. Clinical features include fever, rash and sometimes an inoculation eschar at the bite site [1,3].

Over the past 20 years, there has been a renewed impetus in research on tick-borne rickettsioses in North Africa, particularly in Algeria, due to a drive from clinicians and entomologists. This is also due to the use of modern tools for the diagnosis and detection of Rickettsiae in ticks [1,2]. In 2006, in a prospective study conducted in Oran, Algeria, $60.3 \%$ of patients presenting with a fever, a rash and sometimes an inoculation eschar, were found to have MSF [4]. In 2008, in Batna, Algeria, two human cases of infection due to R. aeschlimannii, an emerging tick-borne rickettsiosis were documented [5]. In 2009, Mouffok et al. reported a unique series of 167 cases of MSF documented through the use of immunofluorescence serology, Western blot, isolation in culture and detection with molecular tools [6]. In addition, tickborne rickettsial agents other than $R$. conorii have been detected in ticks in Algeria, including R. aeschlimannii, R. massiliae [7], $R$. slovaca, $R$. raoultii, $R$. helvetica [8], R. monacensis [8,9] and $R$. africae. Flea-associated rickettsioses, including $R$. felis, an emerging SFG rickettsia and $R$. typhi, the agent of murine typhus, are also known to be emerging infections in Algeria. The purpose of our study was to search for rickettsial etiology in patients presenting a fever, a rash and sometimes an inoculation eschar in Tizi-Ouzou, Algeria over an eighteen-month period.

\section{Materials \& methods}

\subsection{Patients: study site and inclusion criteria}

Between April 2013 and November 2015, all patients presenting with a fever and a skin rash at nine hospitals within the wilaya of Tizi

\footnotetext{
${ }^{*}$ Corresponding author. VITROME, IHU - Méditerranée Infection, 19-21 Boulevard Jean Moulin, 13005, Marseille, France.

E-mail address: philippe.parola@univ-amu.fr (P. Parola).
} 

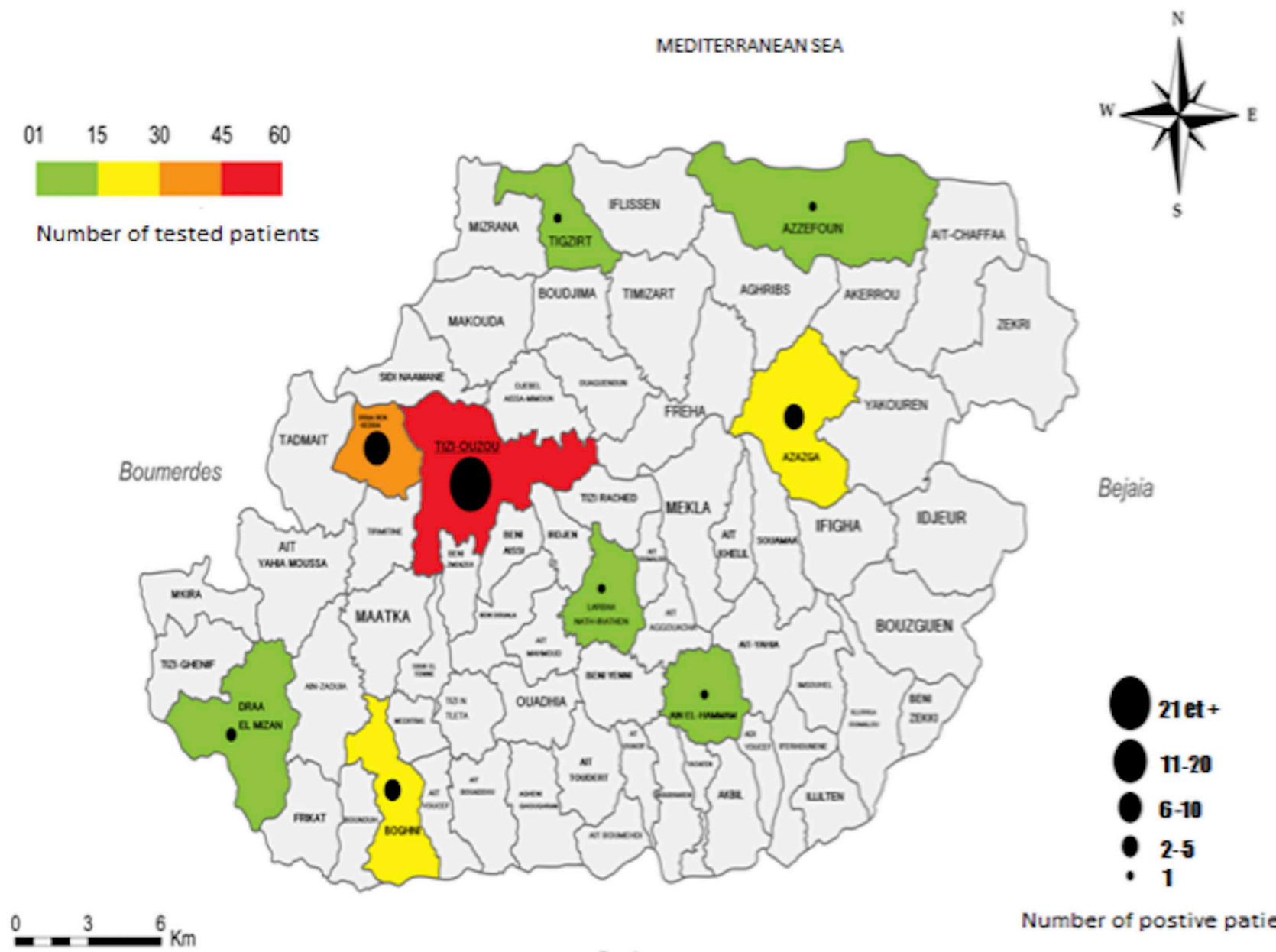

Bouira

Number of postive patients

Fig. 1. Representation of the number of patients included and tested positive in the wilaya of Tizi Ouzou, Algeria.

Ouzou (Fig. 1) Algeria, were included in a prospective follow-up. Clinical and epidemiological data, laboratory results, and information on treatments and outcome were collected. For each patient, an acute serum sample was obtained and, if possible, a convalescent-phase serum sample (collected 1-2 weeks later). A dry sterile swab sample was collected from the eschar of each patient, when present. Scabs were removed from eschars before swabbing. The swabs were rotated vigorously against the eschar and stored at $-20{ }^{\circ} \mathrm{C}$. For four patients, an eschar biopsy sample was collected under sterile conditions. The swab samples and serum samples were transported at $+4{ }^{\circ} \mathrm{C}$ to the reference centre for rickettsial diseases in Marseille, France. Informed consent was obtained from all patients. This study was approved by the ethics committee of the Tizi Ouzou Faculty of Medicine, Algeria.

\subsection{Immunofluorescence assay}

Serum samples were analysed using indirect Immunofluorescence Assay (IFA) against five spotted fever group rickettsial antigens $(R$. conorii conorii, Rickettsia felis, $R$. aeschlimannii, $R$. massiliae) and a typhus group antigen (R.typhi). The IFA test during the acute phase was considered positive if antibody titres were $>1: 128$ for immunoglobulin $\mathrm{G}$ (IgG) and $>1: 64$ for immunoglobulin M (IgM) for the spotted fever group, and $>1: 64$ for IgG and $>1: 32$ for typhus group, as previously described [10]. The IFA was also considered positive in case of seroconversion in paired sera or increase in titres between acute and convalescent phase samples. When cross-reactions were observed, a rickettsial antigen was considered to represent the infectious agent if cumulated titres of IgG and IgM antibodies against this antigen were at least twice as high as those of the others, as previously described [10].

\subsubsection{DNA extraction}

Each eschar swab was immersed in $400 \mu \mathrm{L}$ of G2 Buffer (Qiagen, Hilden, Germany) - lysis buffer - for $1 \mathrm{~h}$ to release eschar materials and $200 \mu \mathrm{L}$ of the supernatant was collected following a quick spin for DNA extraction, as previously described [11]. Genomic DNA was individually extracted from the eschar swab suspension using the EZ1 DNA Tissue extraction kit (Qiagen, Hilden, Germany), according to the manufacturer's instructions. The DNA was then eluted in $100 \mu \mathrm{L}$ of Tris EDTA (TE) buffer using the DNA-extracting EZ1 Advanced XL Robot (Qiagen). DNA was either immediately used or stored at $-20^{\circ} \mathrm{C}$ until molecular analysis. A disinfection of the DNA-extracting EZI Advanced XL Robot was performed after each batch extraction, as per the manufacturer's recommendations, in order to avoid cross-contamination.

\subsubsection{Quantitative PCR}

DNA samples were screened using real-time quantitative PCR (qPCR) with genus-specific primers and probes targeting a fragment of the gltA gene of all spotted fever group Rickettsia species [12] using a CFX Connect ${ }^{\mathrm{TM}}$ Real-Time PCR Detection System (Bio-Rad, Hercules, CA, USA) and the Eurogentec Takyon qPCR kit (Eurogentec, Seraing, Belgium). Subsequently, all positive samples were tested with speciesspecific $R$. massiliae and $R$. conorii qPCR, targeting fragments of an hypothetical protein and the putative acetyltransferase genes respectively $[13,14]$. DNA extract from cultures of $R$. massiliae and $R$. conorii were then used as qPCR positive controls. For each run, a DNA-free PCR mix was used as a qPCR negative control. 


\section{Results}

A total of 190 sera samples from 166 patients $(65.7 \%$ men) were tested. Convalescent serum samples were available for 24 patients (14\%). Sixty-one patients had a positive IFA serology assay. Titres ranged from 1:64 to 1:4096 for IgG, and from 1:32 to 1:2048 for IgM. Forty-nine patients $(80 \%)$ were included during the summer months of June, July and August (Fig. 1). Fifty-six sera samples presented crossreactivity between SFG and typhus group antigens.

However, of these 56 patients, 47 had a cutaneous eschar with a swab sample which showed a positive specific qPCR for $R$. conorii conorii, confirming the diagnosis of MSF. Another ten patients with negative serology had a positive specific qPCR for $R$. conorii conorii on swab eschar sample, making a total of 57 patients with a confirmed diagnosis of MSF.

Of the five remaining patients with IFA positive tests but no molecular data from the eschar, three patients had a positive serology for $R$. typhi without cross-reactivity with SFG rickettsioses. Titres ranged from 1:32 to $1: 512$ for IgG and from 1:64 to $1: 2048$ for IgM, suggesting a diagnosis of murine typhus. Two patients had a positive serology for $R$. felis with IgM titres at 1:64 and negative IgG without cross reactivity with other SFG rickettsiosis and the typhus group. No convalescent serum samples were available. One IFA R. felis positive patient had an eschar, with negative qPCR results of their swab sample.

\subsection{Epidemiological and clinical characteristics of patients}

Patients with confirmed MSF were predominantly male (63.93\%). The mean age of patients was $42.8 \pm 2.9$ years (ranging from 4 to 86 years). Prior to the consultation, 35 (57.4\%) had already received antibiotics (27 had received beta-lactamines, five had received macrolides and three had received cyclins) and four (6.5\%) had received corticosteroids. A total of $34(55.73 \%)$ patients reported contact with dogs, nine (14.7\%) patients reported tick bites, mostly around houses $(77 \%)$ (Table 1). Underlying conditions were present in 22 patients $(36.06 \%)$ and the most frequent were diabetes (13.1\%), high blood pressure (9.8\%) and tobacco consumption (4.9\%) (Table 1). A generalised maculopapular rash, frequently including the palms of the hands and soles of the feet was observed in 51 patients (83.6\%) (Fig. 3), with purpuric elements on the legs in 12 cases (19.67\%). Fifty-seven patients had an inoculation eschar, most often observed on the trunk and legs. It was notable that three patients had two eschars and one had six eschars (Fig. 3). Conjunctivitis was present in 40 cases (65.6\%) (Fig. 3) and was unilateral in five patients. Neurological signs were observed in $13 \%$ of cases and $49.1 \%$ of patients presented digestive symptoms (Table 1 ).

Electrocardiograms (ECG), performed for all patients, were abnormal in five patients (8.2\%), including repolarisation troubles and signs of myocarditis in one case. Chest X-ray findings included interstitial infiltrates in four cases (6.5\%) and pneumonia (one case). Thrombocytopenia was found in 23 patients (37.7\%). Serum elevated liver enzymes, AST and ALT were found in 44 (72.1\%) and 19 (31.1\%) patients, respectively, while hyponatremia was found in 11 patients $(18 \%)$ and leukopenia in eight patients (13.11\%).

\subsection{Patients with possible R. felis infection}

The two patients with IgM positive IFA tests lived in urban areas and had contact with dogs and cats. Both patients had a fever and a maculopapular rash. One patient presented lymphocytic meningitis. The other patient had pulmonary involvement, with alveolar infiltrates visible on the chest X-ray. Both patients had lymphadenitis (cervical and inguinal in the first patient and inguinal only in the second).

\subsection{Patients with murine typhus}

The three patients who tested positive for $R$. typhi were from rural or
Table 1

Underlying conditions and clinical features of patients diagnosed with Rickettsiosis.

\begin{tabular}{|c|c|c|}
\hline & Clinical features & $\begin{array}{l}\text { Number of patients } \\
(\%)\end{array}$ \\
\hline \multirow[t]{8}{*}{ Underlying conditions } & Diabetes & $8(13.1)$ \\
\hline & Hypertension & $6(9.8)$ \\
\hline & Tobacco consumption & 3 (4.9) \\
\hline & Pregnancy & $1(1.6)$ \\
\hline & HIV infection & $1(1.6)$ \\
\hline & Alcohol & $1(1.6)$ \\
\hline & Cardiac disease & $1(1.6)$ \\
\hline & Prostate cancer & $1(1.6)$ \\
\hline \multirow[t]{4}{*}{ General signs } & Fever & $61(100)$ \\
\hline & $\begin{array}{l}\text { Deterioration of general } \\
\text { condition }\end{array}$ & $10(16.4)$ \\
\hline & Deep venous thrombosis (Arm) & $1(1.6)$ \\
\hline & Lymphadenitis & $4(6.5)$ \\
\hline \multirow[t]{7}{*}{ Dermatologic signs } & Maculopapular rash & $51(83.6)$ \\
\hline & Purpuric rash & $12(19.7)$ \\
\hline & Extensive purpuric skin & $2(3.3)$ \\
\hline & Inoculation eschar & $57(93.4)$ \\
\hline & Single & $53(86.9)$ \\
\hline & Double & $3(4.9)$ \\
\hline & Six & $1(1.6)$ \\
\hline \multirow[t]{6}{*}{ Neurologic signs } & Drowsiness & $2(3.3)$ \\
\hline & Coma & $1(1.6)$ \\
\hline & Delirium & $1(1.6)$ \\
\hline & Facial paralysis & $1(1.6)$ \\
\hline & Paraparesia & $1(1.6)$ \\
\hline & Meningitis & $2(3.3)$ \\
\hline \multirow[t]{6}{*}{ Digestive signs } & Vomiting & $6(9.8)$ \\
\hline & Diarrhea & $7(11.5)$ \\
\hline & Constipation & $3(4.9)$ \\
\hline & Abdominal pain & 11(18) \\
\hline & Gastric ulceration & $2(3.3)$ \\
\hline & Splenomegaly & $1(1.6)$ \\
\hline \multirow[t]{2}{*}{ Respiratory signs } & Cough & $8(13.1)$ \\
\hline & Chest infiltrates & $4(6.5 \%)$ \\
\hline \multirow[t]{4}{*}{ Ocular involvement } & Conjunctivitis & $40(65.6)$ \\
\hline & Bilateral & $35(57.4)$ \\
\hline & Unilateral & $5(8.2)$ \\
\hline & Uveitis & $1(1.6)$ \\
\hline \multirow[t]{3}{*}{ Prognosis } & Severe forms & $9(14.7 \%)$ \\
\hline & Multi organ involvement & $2(3.3 \%)$ \\
\hline & Death & $1(1.6 \%)$ \\
\hline
\end{tabular}

suburban areas. None of the patients recalled insect or flea bites and only one reported exposure to rats. None of the patients had eschar. The main symptoms were a fever, myalgias, joint pain, headaches, a cough and a maculopapular rash, spread over the trunk and limbs (Fig. 4), not including the face, the palms of the hands and the soles of the feet. Spleen enlargement was observed in one patient and pulmonary infiltrates were observed in another.

\subsection{Treatment and outcome of patients}

Most patients (47, 77\%), were treated with doxycycline $(200 \mathrm{mg} /$ day for 3-8 days), while other patients were treated with thiamphenicol (3.27\%), fluoroquinolones $(8,13.11 \%)$ and a macrolide antibiotic (josamycin; four, $6.55 \%$, including three children and one pregnant woman). The outcome was favourable for 51 patients (83.6\%). Apyrexia appeared after a mean of 2.92 days (ranging from one to six days). Asthenia and myalgia persisted from between a few weeks to two months (26\%).

A total of nine (14.7\%) patients were hospitalised with a severe infection. Eight had MSF, and one had a possible $R$. felis infection. Of these severe cases, seven men had neurological manifestations (coma: $1.63 \%$, meningitis: $3.27 \%$ ), and two patients (one man and one woman) presented multivisceral involvement. The mean age of these nine patients was 53.5 years. Underlying conditions and comorbidities were 


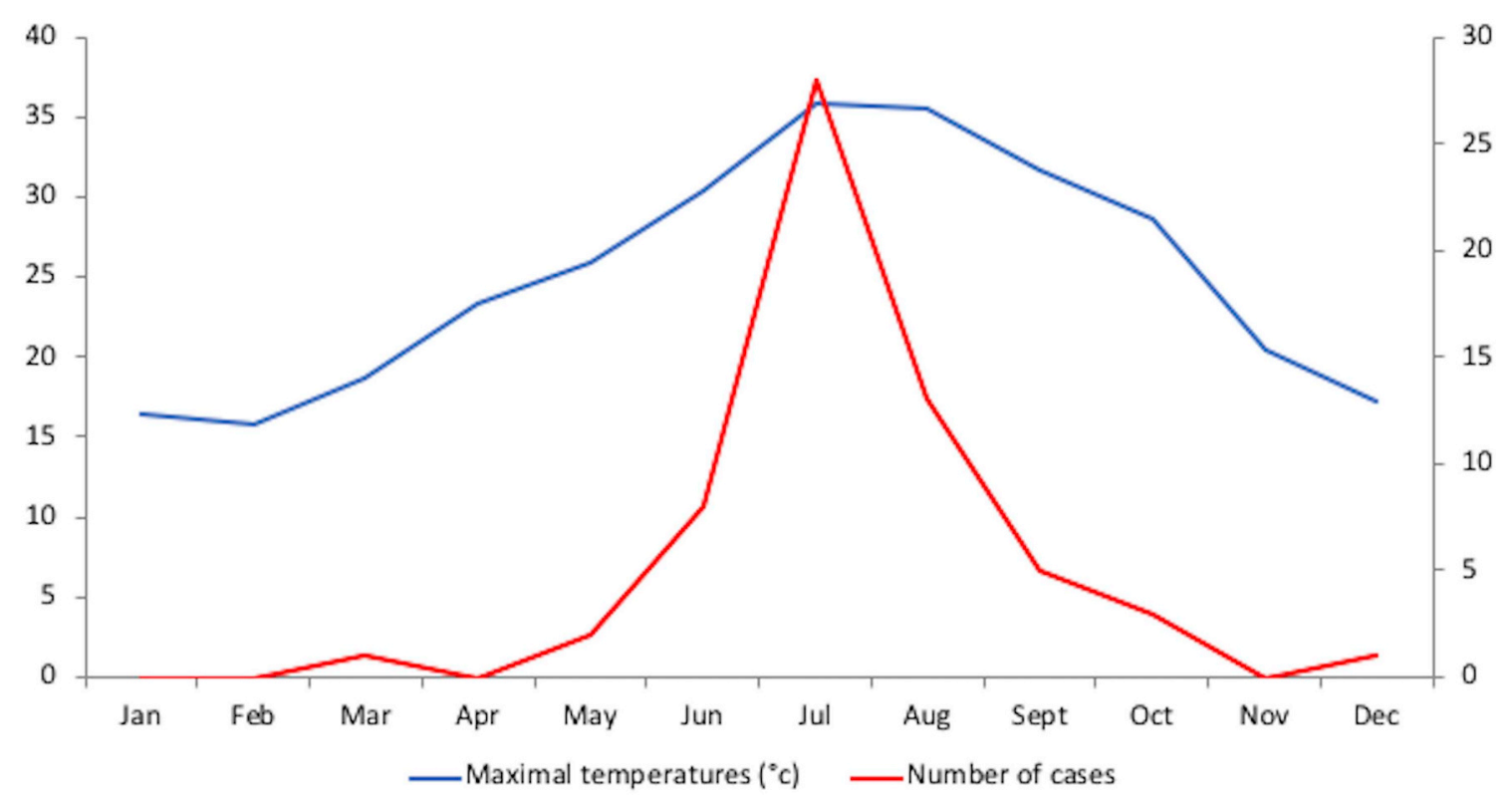

Fig. 2. Repartition of cases and temperatures throughout the year during the inclusion period (2013-2015).

present in these patients, including diabetes (7/9), cardiomyopathy (1/ 9) and chronic alcoholism (1/10). Finally, one MSF patient died despite the administration of doxycycline and fluoroquinolones.

\section{Discussion}

In this paper, we report on the first prospective study on clinical and epidemiological aspects of tick and flea-borne rickettsioses in Tizi Ouzou, a province located in the north of Algeria, and one of the only studies in north Africa in recent decades. Our series reports cases which have been definitely documented using reference methods including IFA and molecular tools on swab eschar samples, performed in an international referral centre for Rickettsioses with adapted negative and positive controls [14].

Of the 166 patients presenting a fever, a rash and a possible inoculation eschar (73 patients), we diagnosed $57 \mathrm{MSF}$, three murine typhus and two possible $R$. felis infections. For nine patients, the serology was positive with a cross reaction between the SFG and typhus groups, and insufficient differences between antigen titres, so that the exact infectious agent could not be determined.

MSF due to Rickettsia conorii conorii is the most frequent rickettsiosis occurring in North Africa. However, there are only fragmentary reports on its epidemiology and clinical aspects in this region, and cases are still rarely documented [6]. In Algeria, no study has previously been conducted in the north central regions. In Batna, eastern Algeria, Mokrani et al. found five cases of MSF due to $R$. conorii conorii in a prospective cohort of 108 adults with febrile exanthema [10]. Oran, western Algeria, is the city were all other studies were conducted by Mouffok et al., reporting a series of 34 cases of FBM in children, and another 167 cases in adults $[4,6]$. The same authors also reported the diagnosis of 39 FBM due to $R$. conorii conorii from eschar swab samples [13].

In our study, MSF cases were encountered in the summer, with $80 \%$ of cases diagnosed between June and August (Fig. 2). Similarly, in Oran [6], most of the MSF patients (80\%) were diagnosed during the summer months, between July and September [4], and the same seasonality has been observed in southern Europe [15-17]. In addition, 5.4\% of patients with MSF had multiple eschars and we found up to six eschars in one patient. This is an infrequently reported feature of MSF [18], because its vector, $R$. sanguineus, has a low tendency to bite humans [19]. In contrast, there are often multiple eschars in other tick borne rickettsioses transmitted by more aggressive ticks like Amblyomma species, which transmit African tick-bite fever in sub-Saharan Africa [20]. Very high summer temperatures were recorded in Tizi Ouzou between 2012 and 2015, which corresponds with our inclusion period. Similarly, the highest summer temperatures in the past decade were recorded in Oran in 2003, when an increase of MSF cases was also observed, with $16.3 \%$ of patients having more than one "tâche noire" [4]. A similar correlation between the increase in the number of MSF cases and high temperatures was observed in southern Europe during the 1970s and, more recently, in Spain, Sardinia and France [21-24]. Changes in tick behaviour resulting from high temperature may explain these aspects of the disease. Parola et al. have demonstrated in an experimental model (rabbit) that immature stages of $R$. sanguineus become highly aggressive when exposed to higher temperatures [19]. In a similar experimental design, Socolovoschi et. al also demonstrated the effects of higher temperature on the behaviour of all stages of Rh. sanguineus ticks [25]. In Marseille, during a particularly warm summer, an alcoholic homeless man died from severe MSF, after a total of 22 ticks were found attached to various parts of his body [26].

In our sample, the prevalence of severe forms of MSF was $14.75 \%$, with mainly neurological symptoms (meningitis, coma) (Table 1), multi-organ failure and myocarditis. One patient died. MSF is a falsely benign disease, with some severe forms being described since the first studies on this disease. Between 1983 and 1984, active surveillance of MSF in Marseille and the surrounding area identified 5\% of patients with a severe form of the disease [27]. In Oran, the prevalence of severe forms of MSF reached $49.1 \%$, and $6.6 \%$ of the 167 patients presented with neurological symptoms, multi-organ involvement, and a $50 \%$ death rate [4]. In 1997, in Beja, a district in southern Portugal, the casefatality rate among patients hospitalised with MSF was 32.3\%, which remains the highest documented rate at this site since 1994 [28]. Risk factors for fatal outcome were diabetes, vomiting, dehydration and uraemia [28]. Classic risk factors for severe forms include advanced age, immunodepression, chronic alcoholism, glucose-6-phosphate dehydrogenase deficiency, prior prescription of an inappropriate antibiotic, and delayed treatment [3]. In our study, of the nine patients with severe forms, seven $(77.8 \%)$ were diabetic. As for treatment, fluoroquinolones have been associated with poor outcomes in MSF [29], probably due to toxin-antitoxin module upregulation [30], so that it should not be used empirically in the presence of clinical features of MSF. The rapid initiation of doxycycline is the right strategy in this case. 

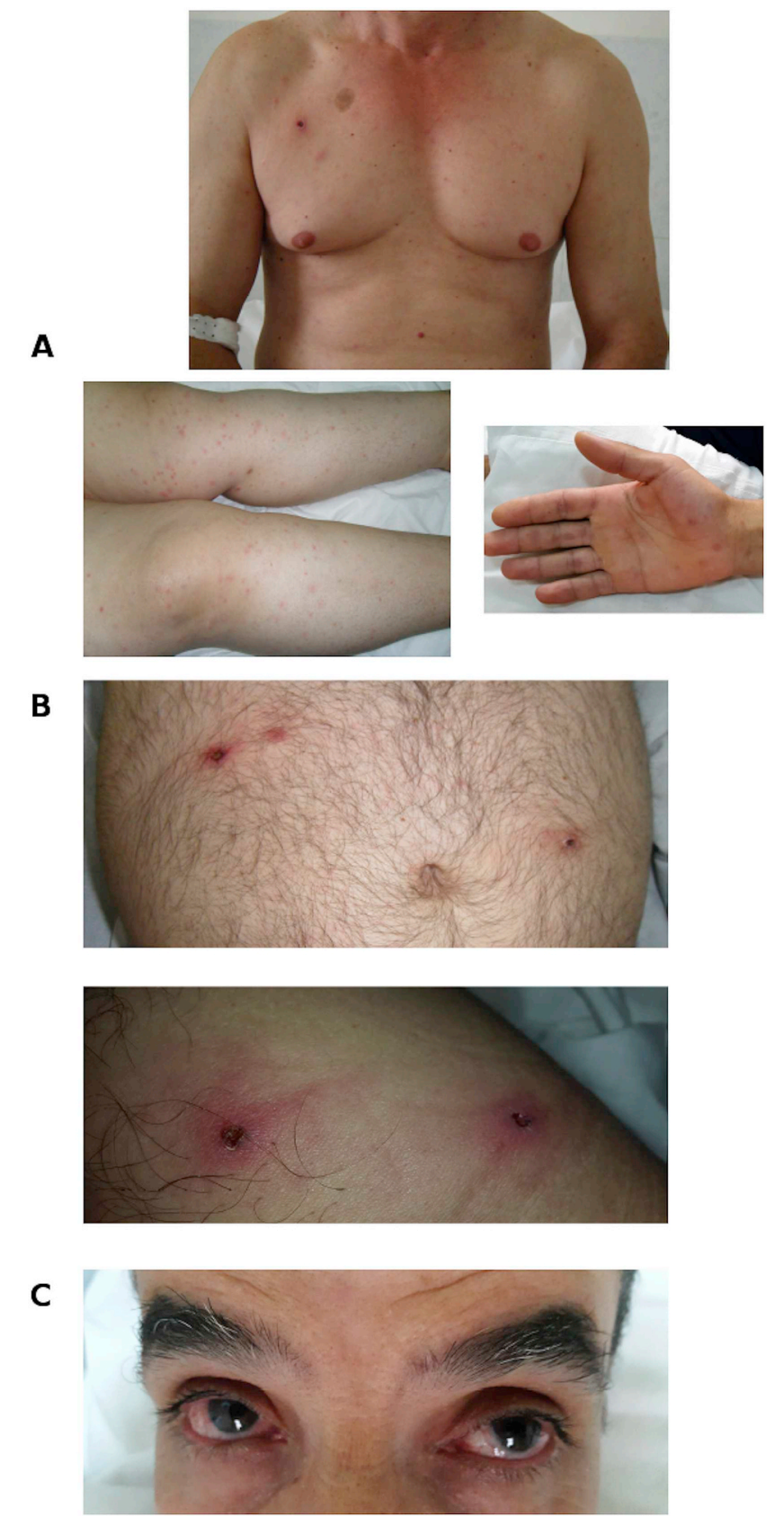

Fig. 3. Clinical presentation of MSF. A, B,C: Maculo-papular rash of MSF involving the palms of the hands and soles of the feet. Panel D, E: Multiple inoculation eschars in MSF patients. Panel F: Conjunctivitis.

Other clinical aspects were in accordance with the description of the disease, including an abrupt onset, high fever, headache, arthromyalgia and a typical maculopapular rash that often involved the palms of the hands and soles of the feet, but frequently spared the face [31]. Different aspects of the rash were also observed, including purpuric forms, particularly in older patients and in severe cases. In our study, we found a high rate of conjunctivitis (65. 6\%) and one patient presented uveitis. Ocular involvement has been described in MSF [32,33]. Unilateral conjunctivitis is frequently due to direct inoculation after contact with infected fluids (crushed ticks for example) [34,35]. Uveitis, retinitis and chorioretinitis, which were also described in the Oran series [6], result from vasculitis due to Rickettsia [19,36].

Murine typhus was the second most frequent rickettsiosis (three cases), after MSF in our study. This rickettsiosis is mainly transmitted by the rat flea Xenopspylla cheopis and has been sporadically reported in
Algeria [10]. In 2008, Mouffok et al. reported two cases diagnosed by serology in Oran. As in our study, patients did not present an inoculation eschar. This is in accordance with what is known about the inconstant presence of eschar in murine typhus from patients. It is frequently a mild disease with unspecific signs. Clinical signs include fever, arthralgia, headache and a slight rash which can be confused with a viral one [37]. Diagnosis may also be missed because a rash, which is the hallmark of rickettsioses, is frequently absent [38]. In Batna, Mokrani et al. found also murine typhus in four patients, representing the second most frequent rickettsioses after MSF [10].

Possible $R$. felis infection was found in two patients in our study, including one patient presenting an eschar. R. ickettsia felis is an emerging rickettsia, with a hundred cases reported to date around the world [39]. The bacterium has also been found in $15 \%$ of cases of fever of unknown origin in sub-Saharan Africa [40]. The cat flea, Ctenocephalides felis, has long been considered as the main vector, but recently, Anopheles gambiae mosquitoes, which are well known as vectors of malaria, have been implicated as potential vectors [39]. In Algeria, $R$. felis has previously been detected in various cat fleas from the area of Oran and Algiers [41-43]. Mokrani et al. reported the first cases $(n=2)$ of $R$. felis infection in Batna [10], and two other cases were reported among 257 febrile patients in Oran [44], suggesting that this pathogen is also emergent in Algeria. In our study, one patient with possible $R$. felis infection had lymphocytic meningitis, a characteristic that has never before been described in Algeria in this infection. Only a few cases of $R$. felis infection with central nervous system involvement have been reported in the literature $[45,46]$.

For nine patients, the serology was positive with cross reactivity between SFG and typhus group, so that the exact rickettsial species could not be determined. In Algeria, other tick-borne rickettsioses have been described, including $R$. aeschlimanni (two cases in Batna) [5]. Also, $R$. monacensis, $R$. helvetica and $R$. slovaca [9,47-49] have been detected in ticks. Further studies are needed to better understand the epidemiology of these rickettsioses in Algeria.

One limitation of our study is the lack of convalescent serum specimens, that were only available for 24 patients. More samples would have helped detecting more rickettsial infections. Another limitation was the absence of Western blot and cross adsorption assays to determine the exact species involved, due to a lack of sera. However, only a few patients were not definitely documented, as specific qPCR on eschar swabs allowed for the diagnosis of 57 MSF due to $R$. conorii conorii, ten of whom had a negative first serology. Our study is one of the few using eschar swabs for the direct diagnosis of rickettsial diseases in addition to IF serology [13,21,50-53]. This method is much less invasive than cutaneous biopsy of the eschar and has shown encouraging results for the detection of $R$. conorii conorii and $R$. africae [54,55]. In Algeria, it has already been used in MSF in Oran with feedback from healthcare providers and patients showing that they both prefer collecting swab samples rather than biopsy samples (46 versus 5 , and 57 versus 2 , respectively; $\mathrm{p}=0.0001$ ) [13]. This technique has also been used in Tunisia, for the detection of $R$. conorii and $R$. typhi [51].

Given the potentially severe outcome of rickettsioses, our work has implications for travel medicine practitioners. They should include advice on tick bite prevention in the pre-travel consultation for patients going to Algeria and North Africa. Also, SFG rickettsioses should be suspected in travellers returning from Algeria with febrile exanthema. In these patients, an inoculation eschar should be searched for, through careful clinical examination.

\section{Conclusion}

We showed that tick-borne SFG rickettsioses are frequent in the Tizi Ouzou region, with MSF being the most frequent infection, followed by murine typhus and possible $R$. felis infection. Rickettsioses can be severe diseases and clinicians should suspect and promptly treat MSF with 
A

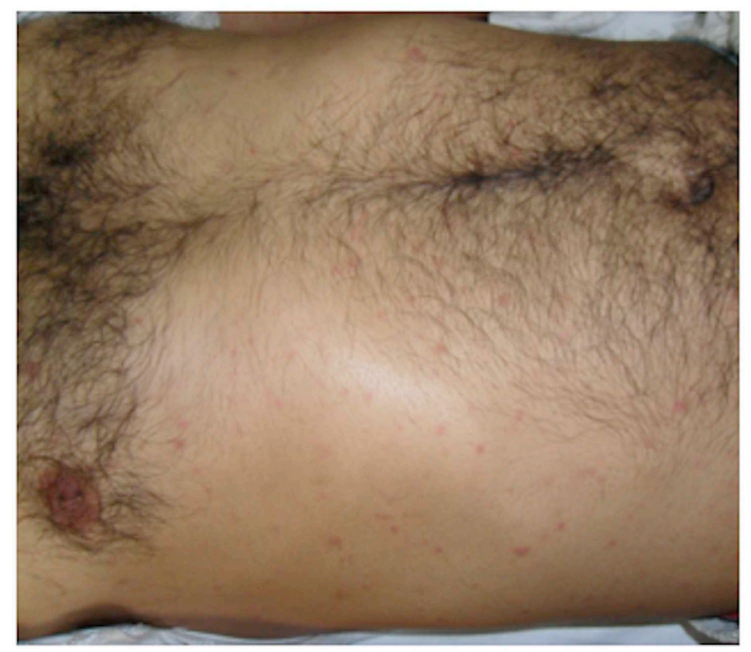

B

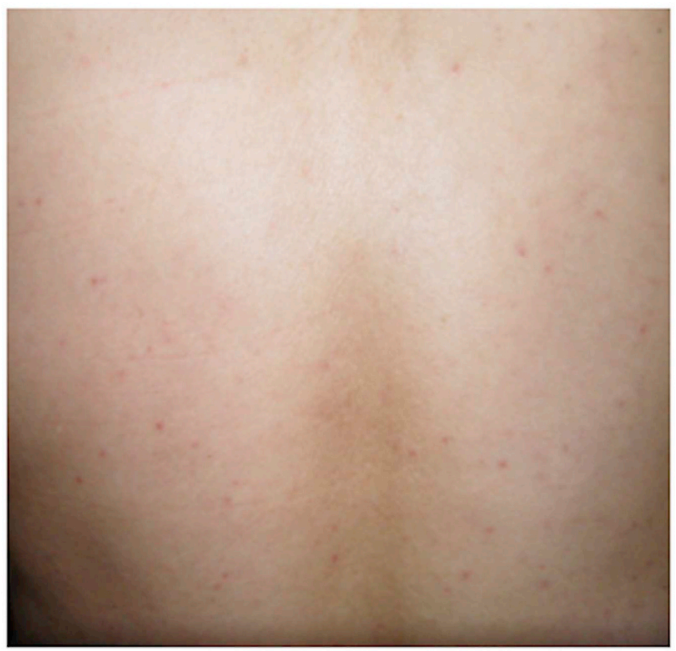

Fig. 4. Rash of one patient with Murine typhus. Panel A: rash on the abdomen and trunk. Panel B: rash on the back.

doxycycline in patients presenting a fever and rash. IFA and qPCR on eschar swab samples should be routinely used in endemic areas in Algeria and in travellers returning from this area. This could lead to early diagnosis and better prognosis through early treatment.

\section{References}

[1] Parola P, Paddock CD, Socolovschi C, Labruna MB, Mediannikov O, Kernif T, et al. Update on tick-borne rickettsioses around the world: a geographic approach. Clin Microbiol Rev 2013;26:657-702. https://doi.org/10.1128/CMR.00032-13.

[2] Kernif T, Leulmi H, Raoult D, Parola P. Emerging tick-borne bacterial pathogens. Microbiol Spectr 2016;4. https://doi.org/10.1128/microbiolspec.EI10-0012-2016.

[3] Raoult D, Roux V. Rickettsioses as paradigms of new or emerging infectious diseases. Clin Microbiol Rev 1997;10:694-719.

[4] Mouffok N, Benabdellah A, Richet H, Rolain JM, Razik F, Belamadani D, et al. Reemergence of rickettsiosis in oran, Algeria. Ann N Y Acad Sci 2006;1078:180-4. https://doi.org/10.1196/annals.1374.033.

[5] Mokrani N, Parola P, Tebbal S, Dalichaouche M, Aouati A, Raoult D. Rickettsia aeschlimannii infection, Algeria. Emerg Infect Dis 2008;14:1814-5. https://doi.org/ 10.3201/eid1411.071221.

[6] Mouffok N, Parola P, Lepidi H, Raoult D. Mediterranean spotted fever in Algerianew trends. Int J Infect Dis IJID Off Publ Int Soc Infect Dis 2009;13:227-35. https:// doi.org/10.1016/j.ijid.2008.06.035.

[7] Bitam I, Parola P, Matsumoto K, Rolain JM, Baziz B, Boubidi SC, et al. First molecular detection of R. conorii, R. aeschlimannii, and R. massiliae in ticks from Algeria. Ann N Y Acad Sci 2006;1078:368-72. https://doi.org/10.1196/annals. 1374.073.

[8] Kernif T, Socolovschi C, Bitam I, Raoult D, Parola P. Vector-borne rickettsioses in north Africa. Infect Dis Clin North Am 2012;26:455-78. https://doi.org/10.1016/j. idc.2012.03.007.

[9] Dib L, Bitam I, Bensouilah M, Parola P, Raoult D. First description of Rickettsia monacensis in Ixodes ricinus in Algeria. Clin Microbiol Infect Off Publ Eur Soc Clin Microbiol Infect Dis 2009;15(Suppl 2):261-2. https://doi.org/10.1111/j.14690691.2008.02277.x.

[10] Mokrani K, Tebbal S, Raoult D, Fournier P-E. Human rickettsioses in the Batna area, eastern Algeria. Ticks Tick-Borne Dis 2012;3:364-6. https://doi.org/10.1016/j. ttbdis.2012.10.017.

[11] Le Viet N, Laroche M, Thi Pham HL, Viet NL, Mediannikov O, Raoult D, et al. Use of eschar swabbing for the molecular diagnosis and genotyping of Orientia tsutsugamushi causing scrub typhus in Quang Nam province, Vietnam. PLoS Negl Trop Dis 2017;11:e0005397https://doi.org/10.1371/journal.pntd.0005397.

[12] Socolovschi C, Reynaud P, Kernif T, Raoult D, Parola P. Rickettsiae of spotted fever group, Borrelia valaisiana, and Coxiella burnetii in ticks on passerine birds and mammals from the Camargue in the south of France. Ticks Tick-Borne Dis 2012;3:355-60. https://doi.org/10.1016/j.ttbdis.2012.10.019.

[13] Mouffok N, Socolovschi C, Benabdellah A, Renvoise A, Parola P, Raoult D. Diagnosis of rickettsioses from eschar swab samples, Algeria. Emerg Infect Dis 2011;17. https://doi.org/10.3201/eid1710.110332. 1968-9.

[14] Renvoisé A, Delaunay P, Blanchouin E, Cannavo I, Cua E, Socolovschi C, et al. Urban family cluster of spotted fever rickettsiosis linked to Rhipicephalus sanguineus infected with Rickettsia conorii subsp. caspia and Rickettsia massiliae. Ticks Tick-Borne Dis 2012;3:389-92. https://doi.org/10.1016/j.ttbdis.2012.10.008.

[15] Bacellar F, Sousa R, Santos A, Santos-Silva M, Parola P. Boutonneuse fever in Portugal: 1995-2000. Data of a state laboratory. Eur J Epidemiol 2003;18:275-7.
https://doi.org/10.1023/A:1023391212354.

[16] Punda-Polić V, Luksić B, Capkun V. Epidemiological features of Mediterranean spotted fever, murine typhus, and Q fever in Split-Dalmatia County (Croatia), 19822002. Epidemiol Infect 2008;136:972-9. https://doi.org/10.1017/ S0950268807009491.

[17] Dzelalija B, Punda-Polic V, Medic A, Dobec M. Rickettsiae and rickettsial diseases in Croatia: implications for travel medicine. Travel Med Infect Dis 2016;14:436-43. https://doi.org/10.1016/j.tmaid.2016.06.010.

[18] Olmer D. Sur une infection épidémique, avec exanthème, de nature indéterminée. Mars Med 1925:22:1291-3.

[19] Parola P, Socolovschi C, Jeanjean L, Bitam I, Fournier P-E, Sotto A, et al. Warmer weather linked to tick attack and emergence of severe rickettsioses. PLoS Negl Trop Dis 2008;2:e338. https://doi.org/10.1371/journal.pntd.0000338.

[20] Raoult D, Fournier PE, Fenollar F, Jensenius M, Prioe T, de Pina JJ, et al. Rickettsia africae, a tick-borne pathogen in travelers to sub-Saharan Africa. N Engl J Med 2001;344:1504-10. https://doi.org/10.1056/NEJM200105173442003.

[21] Wang JM, Hudson BJ, Watts MR, Karagiannis T, Fisher NJ, Anderson C, et al. Diagnosis of Queensland tick typhus and African tick bite fever by PCR of lesion swabs. Emerg Infect Dis 2009;15:963-5. https://doi.org/10.3201/eid1506.080855.

[22] Gilot B, Laforge ML, Pichot J, Raoult D. Relationships between the Rhipicephalus sanguineus complex ecology and Mediterranean spotted fever epidemiology in France. Eur J Epidemiol 1990;6:357-62.

[23] Vescio MF, Piras MA, Ciccozzi M, Carai A, Farchi F, Maroli M, et al. Socio-demographic and climatic factors as correlates of Mediterranean spotted fever (MSF) in northern Sardinia. Am J Trop Med Hyg 2008;78:318-20.

[24] Mansueto S, Tringali G, Walker DH. Widespread, simultaneous increase in the incidence of spotted fever group rickettsioses. J Infect Dis 1986;154:539-40.

[25] Socolovschi C, Raoult D, Parola P. Influence of temperature on the attachment of Rhipicephalus sanguineus ticks on rabbits. Clin Microbiol Infect Off Publ Eur Soc Clin Microbiol Infect Dis 2009;15(Suppl 2):326-7. https://doi.org/10.1111/j.14690691.2008.02260.x.

[26] Hemmersbach-Miller M, Parola P, Raoult D, Brouqui P. A homeless man with maculopapular rash who died in Marseille, France. Clin Infect Dis Off Publ Infect Dis Soc Am 2004;38(1412). https://doi.org/10.1086/420747. 1493-4.

[27] Raoult D, Zuchelli P, Weiller PJ, Charrel C, San Marco JL, Gallais H, et al. Incidence, clinical observations and risk factors in the severe form of Mediterranean spotted fever among patients admitted to hospital in Marseilles 1983-1984. J Infect 1986;12:111-6.

[28] de Sousa R, Nóbrega SD, Bacellar F, Torgal J. Mediterranean spotted fever in Portugal: risk factors for fatal outcome in 105 hospitalized patients. Ann N Y Acad Sci 2003;990:285-94.

[29] Botelho-Nevers E, Socolovschi C, Raoult D, Parola P. Treatment of Rickettsia spp. infections: a review. Expert Rev Anti Infect Ther 2012;10:1425-37. https://doi.org/ 10.1586/eri.12.139.

[30] Botelho-Nevers E, Edouard S, Leroy Q, Raoult D. Deleterious effect of ciprofloxacin on Rickettsia conorii-infected cells is linked to toxin-antitoxin module up-regulation. J Antimicrob Chemother 2012;67:1677-82. https://doi.org/10.1093/jac/ dks089.

[31] Raoult D, Jean-Pastor MJ, Xeridat B, Garnier JM, Weiller PJ, Garcin G, et al. [Mediterranean boutonneuse fever. Apropos of 154 recent cases]. Ann Dermatol Venereol 1983;110:909-14.

[32] Agahan ALD, Torres J, Fuentes-Páez G, Martínez-Osorio H, Orduña A, Calonge M. Intraocular inflammation as the main manifestation of Rickettsia conorii infection. Clin Ophthalmol Auckl NZ 2011;5:1401-7. https://doi.org/10.2147/OPTH. S21257.

[33] Abroug N, Khochtali S, Kahloun R, Mahmoud A, Attia S, Khairallah M. Ocular 
manifestations of rickettsial disease. J Infect Dis Ther 2014;2:1-4. https://doi.org/ 10.4172/2332-0877.1000140.

[34] Brissos J, de Sousa R, Santos AS, Gouveia C. Rickettsial infection caused by accidental conjunctival inoculation. BMJ Case Rep 2015;2015. https://doi.org/10. 1136/bcr-2014-207029.

[35] Parola P, Paddock CD, Raoult D. Tick-borne rickettsioses around the world: emerging diseases challenging old concepts. Clin Microbiol Rev 2005;18:719-56. https://doi.org/10.1128/CMR.18.4.719-756.2005.

[36] Caisso C, Payan J, Dunais B, Neri D, Vassallo M. A case of uveitis due to Rickettsia conorii infection in Southeastern France. Ticks Tick-Borne Dis 2016;7:338-41. https://doi.org/10.1016/j.ttbdis.2015.12.004.

[37] Mouffok N, Parola P, Raoult D. Murine typhus, Algeria. Emerg Infect Dis 2008;14:676-8. https://doi.org/10.3201/eid1404.071376.

[38] Parola P, Vogelaers D, Roure C, Janbon F, Raoult D. Murine typhus in travelers returning from Indonesia. Emerg Infect Dis 1998;4:677-80. https://doi.org/10. 3201/eid0404.980423.

[39] Angelakis E, Mediannikov O, Parola P, Raoult D. Rickettsia felis: the complex journey of an emergent human pathogen. Trends Parasitol 2016;32:554-64. https://doi.org/10.1016/j.pt.2016.04.009.

[40] Delord M, Socolovschi C, Parola P. Rickettsioses and Q fever in travelers (20042013). Travel Med Infect Dis 2014;12:443-58. https://doi.org/10.1016/j.tmaid. 2014.08.006.

[41] Bitam I, Parola P, De La Cruz KD, Matsumoto K, Baziz B, Rolain J-M, et al. First molecular detection of Rickettsia felis in fleas from Algeria. Am J Trop Med Hyg 2006;74:532-5

[42] Bitam I, Baziz B, Kernif T, Harrat Z, Parola P, Raoult D. Molecular detection of Rickettsia typhi and Rickettsia felis in fleas from Algeria. Clin Microbiol Infect Off Publ Eur Soc Clin Microbiol Infect Dis 2009;15(Suppl 2):255-6. https://doi.org/10. 1111/j.1469-0691.2008.02275.x.

[43] Bessas A, Leulmi H, Bitam I, Zaidi S, Ait-Oudhia K, Raoult D, et al. Molecular evidence of vector-borne pathogens in dogs and cats and their ectoparasites in Algiers, Algeria. Comp Immunol Microbiol Infect Dis 2016;45:23-8. https://doi.org/10. 1016/j.cimid.2016.01.002

[44] Mediannikov O, Socolovschi C, Edouard S, Fenollar F, Mouffok N, Bassene H, et al. Common epidemiology of Rickettsia felis infection and malaria, Africa. Emerg
Infect Dis 2013;19:1775-83. https://doi.org/10.3201/eid1911.130361.

[45] Lindblom A, Severinson K, Nilsson K. Rickettsia felis infection in Sweden: report of two cases with subacute meningitis and review of the literature. Scand J Infect Dis 2010;42:906-9. https://doi.org/10.3109/00365548.2010.508466.

[46] Salva I, de Sousa R, Gouveia C. Rickettsial meningitis. BMJ Case Rep 2014;2014. https://doi.org/10.1136/bcr-2013-203283.

[47] Benredjem W, Leulmi H, Bitam I, Raoult D, Parola P. Borrelia garinii and Rickettsia monacensis in Ixodes ricinus ticks, Algeria. Emerg Infect Dis 2014;20:1776-7. https://doi.org/10.3201/eid2010.140265.

[48] Djerbouh A, Kernif T, Beneldjouzi A, Socolovschi C, Kechemir N, Parola P, et al. The first molecular detection of Rickettsia aeschlimannii in the ticks of camels from southern Algeria. Ticks Tick-Borne Dis 2012;3:374-6. https://doi.org/10.1016/j. ttbdis. 2012.10.014.

[49] Kernif T, Messaoudene D, Ouahioune S, Parola P, Raoult D, Bitam I. Spotted fever group rickettsiae identified in Dermacentor marginatus and Ixodes ricinus ticks in Algeria. Ticks Tick-Borne Dis 2012;3:380-1. https://doi.org/10.1016/j.ttbdis.2012. 10.012.

[50] Solary J, Socolovschi C, Aubry C, Brouqui P, Raoult D, Parola P. Detection of Rickettsia sibirica mongolitimonae by using cutaneous swab samples and quantitative PCR. Emerg Infect Dis 2014;20:716-8. https://doi.org/10.3201/eid2004. 130575.

[51] Khrouf F, Sellami H, Elleuch E, Hattab Z, Ammari L, Khalfaoui M, et al. Molecular diagnosis of Rickettsia infection in patients from Tunisia. Ticks Tick-Borne Dis 2016;7:653-6. https://doi.org/10.1016/j.ttbdis.2016.02.010.

[52] Bechah Y, Socolovschi C, Raoult D. Identification of rickettsial infections by using cutaneous swab specimens and PCR. Emerg Infect Dis 2011;17:83-6. https://doi. org/10.3201/eid1701.100854.

[53] Socolovschi C, Renvoisé A, Brouqui P, Parola P, Raoult D. The use of eschar swabs for the diagnosis of African tick-bite fever. Ticks Tick-Borne Dis 2012;3:361-3. https://doi.org/10.1016/j.ttbdis.2012.10.018.

[54] Bechah Y, Socolovschi C, Raoult D. Identification of rickettsial infec-tions by using cutaneous swab specimens and PCR. Emerg Infect Dis 2011;17:83-6.

[55] Socolovschi C, Renvoisé A, Brouqui P, Parola P, Raoult D. The use of eschar swabs for the diagnosis of African tick-bite fever. 2012. 